\title{
Agricultural production diversity and child nutrition in Ethiopia
}

\author{
Maryia Bakhtsiyarava $^{1}$ (D) Kathryn Grace ${ }^{2}$
}

Received: 11 February 2020 / Accepted: 30 April 2021 / Published online: 5 June 2021

(C) The Author(s) 2021

\begin{abstract}
This study investigates how two aspects of agricultural production diversity - farm production diversity and composition of production - relate to child height-for-age and weight-for-height in Ethiopia. We use longitudinal data on child anthropometric measurements, household farm production diversity and farm production composition from the Ethiopia Socioeconomic Survey for 2011, 2013, and 2015 available through the World Bank. Using longitudinal fixed effects models, we show that an increase in farm production diversity reduces the risk of chronic food insecurity (child height-for-age) but has no impact on acute measures of food insecurity (child weight-for-height). Results also suggest that, in a context of poor rainfall, more diversity in farm production can adversely impact child height-for-age, although livestock sales might mitigate that detrimental effect. These findings highlight the importance of considering the relationship between farm-level food production and child nutrition in a context of climate change.
\end{abstract}

Keywords Agricultural production diversity $\cdot$ Child malnutrition $\cdot$ Agricultural livelihoods $\cdot$ Climatic conditions $\cdot$ Ethiopia

\section{Introduction}

Child malnutrition - an outcome of food insecurity reflecting insufficient food and nutrient intake - has negative implications for children's educational attainment, lifetime earnings, and health later in life, resulting in high social and economic costs (Black et al., 2008; Victora et al., 2008). The reasons underlying why an individual child is malnourished are complex and multi-dimensional, representing an interaction of individual-, household-, community-, and regional- level factors related to biological, behavioral, socioeconomic, and environmental conditions (Jones et al., 2013; Phalkey et al., 2015; UNICEF, 1991).

Maryia Bakhtsiyarava

mariab@berkeley.edu

Kathryn Grace

klgrace@umn.edu

1 Institute of Urban and Regional Development, University of California - Berkeley, Berkeley, CA 94720, USA

2 Department of Geography, Environment and Society, University of Minnesota - Twin Cities, 267 19th Ave S, Minneapolis, MN 55455, USA
Food insecurity is one of the underlying causes of child malnutrition. Food insecurity results from failures in the food system related to access, availability, utilization of nutritious foods (body's ability to digest and absorb nutrients), or when food supplies and costs are inconsistent (Brown et al., 2015; FAO, 1996). In rural households in low-income countries, local, small-scale agriculture is often the main source of food and income. Consequently, policies aimed at reducing hunger and improving nutrition used to routinely encourage increasing household- and country-level staple crop production (Michler \& Josephson, 2017). However, recently there has been a push to design and implement "nutritionally sensitive" agricultural policies and interventions that not only focus on adequate calorie intake but also work to ensure that individuals have access to adequate and diverse sources of calories that satisfy micronutrient, vitamin, and protein consumption requirements (Pinstrup-Andersen, 2013; Ruel et al., 2013, 2018). Promoted interventions include home gardening, cultivation of nutrient-rich tuber and legume crops, cultivation of vitamin-supplemented and biofortified crops (e.g., vitamin-Afortified sweet potato), donation of poultry and gardening tools, as well as livestock transfers (Berti et al., 2004; Ruel et al., 2018).

The goal of this study is to evaluate how variation in anthropometric indicators of child malnutrition in Ethiopia relates to variation in agricultural production diversity. Our 
measurement of farm-level agricultural production diversity includes two farm-level indicators - production diversity, the count of food groups produced on the farm that contribute to household dietary diversity; and production composition, measuring shares of cereals, roots, pulses, fruits, and vegetables relative to all cultivated food crops, and production of meat, milk, and eggs. Our focus on how variation in agricultural production diversity at different scales (household- and community-levels) relates to child malnutrition advances the existing literature. We also situate this analysis within the context of climate change and consider the potential for small-scale variations in rainfall levels to complicate a relationship between agricultural production and child health (e.g., Randell et al., 2021). To conduct this analysis we use longitudinal survey data from the Ethiopia Socioeconomic Survey in 2011, 2013 and 2015 (ESS) collected in conjunction with the World Bank Living Standards Measurement Study (LSMS) with $5-\mathrm{km}$ monthly gridded climate data from the Climate Hazards Group InfraRed Precipitation with Station data (CHIRPS). Most studies on the relationship between agricultural diversity and child nutrition have relied on crosssectional data (notable exceptions include (Chegere \& Stage, 2020; Dillon et al., 2015; Islam et al., 2018; Slavchevska, 2015), so the use of longitudinal fixed effects models results in more reliable estimates compared to those from the crosssectional studies, which in turn can be more confidently used to inform policy.

\section{Background and setting}

\subsection{Child malnutrition}

In this study we evaluate variation in child anthropometric measures, height-for-age z-scores and weight-for-height $\mathrm{z}$ scores, to measure food insecurity-related malnutrition. A child is stunted/wasted if their height-for-age z-score (HAZ)/ weight-for-height z-score (WHZ) is more than two standard deviations below the World's Health Organization (WHO) Child Growth Standards median (WHO \& de Onis, 2006). Stunting reflects chronic malnutrition and can be caused by insufficient nutrition during the in utero period, failure to receive proper nutrition for an extended period of time, and can be aggravated by repeated infections (Dorelien, 2015; IFPRI, 2016). Stunted children are at risk of developing health complications later in life and less likely to achieve levels of educational attainment and earnings compared to well-nourished children (Dewey \& Begum, 2011; Victora et al., 2008).

Wasting describes child's weight relative to height and is a measure of acute malnutrition. Wasting can be brought about by conditions during fetal development such as intrauterine growth retardation (Shrimpton et al., 2001; Victora et al., 2010) or rapid weight loss, which in turn can be caused by severe infections or hunger (Victora, 1992). Inadequate diets can lead to both stunting and wasting, but an improvement in energy intake can reverse wasting, whereas gains in heightfor-age z-scores do not occur as quickly, rendering stunting potentially irreversible (Victora, 1992). Unlike stunting, wasting has been understudied as a food security outcome (Brown et al., 2020). We focus on HAZ and WHZ as they are both hypothesized outcomes of, among other determinants factors, food insecurity, but describe it from different angles: height-for-age and stunting are reflective of prolonged periods of inadequate malnutrition, whereas weight-for-height and wasting are reflective of short-term, recent malnutrition (Jones et al., 2013).

\subsection{Food security in Ethiopia}

The prevalence of child stunting and wasting in Ethiopia is $38 \%$ and $10 \%$, respectively (CSA-ICF, 2017), which makes Ethiopia home to one of the largest populations of malnourished children in the world. Several factors contribute to Ethiopia's high vulnerability to food insecurity and high prevalence of child malnutrition: weather/climate variability, low rates of technology adoption, environmental degradation, and structural and infrastructural peculiarities (Demeke et al., 2004). Agriculture employs $80 \%$ of Ethiopians and is the primary source of food and income for the majority of the population (Demeke et al., 2004; Mohamed, 2017). Agricultural productivity is constrained because most Ethiopians are smallholder farmers with an average size of a land holding of 1.38 ha (CSA \& World Bank, 2017). The state owns all land in Ethiopia and grants farmers rights to cultivate it but not sell it (Ali et al., 2007; Josephson et al., 2014), which prevents farmers from accumulating land as a form of capital and enhancing their resilience in the face of environmental or economic shocks (Bogale et al., 2006; Carter et al., 2007; Holden \& Ghebru, 2016). A lack of political stability caused Ethiopians to experience three structural changes in agricultural sector within a span of several decades, from semifeudalism to state socialism to market liberalization (Devereux \& Sussex, 2000), which was accompanied by a decline in the standards of living and contributed to food insecurity (Devereux \& Sussex, 2000; Feleke et al., 2005).

Environmental conditions present an additional challenge to the food security situation in Ethiopia. Since the mid-70s, spring and summer rainfall in Ethiopia has decreased by about 20\% (Funk et al., 2012), with negative ramifications for yields and pasture conditions. The droughts have gotten more expansive as there has been a steady increase in the proportion of Ethiopian population affected by the droughts since 1997 (Demeke et al., 2004). Ethiopia's agriculture depends on rainfall as a source of moisture, and frequent droughts damage or destroy crops, undermining households' livelihoods and the ability to maintain an adequate diet. Ethiopia recently 
experienced a meteorological ${ }^{1}$ drought in 2015, when, from February to September 2015 - a time period that overlaps with the two main rainy seasons, the country received a half to three-quarters of its normal rainfall (Philip et al., 2018). The two main rainy seasons in Ethiopia - belg (a short season from March to May) and kiremt (June - September) - together amount to about $90 \%$ of total rainfall but both came late in 2015 and were characterized by erratic and delayed rainfall (Philip et al., 2018). The 2015 drought was particularly severe in northern and central parts of the country and led to the loss of 50 to $90 \%$ (depending on the crop) of total crop production (FAO, 2017), loss of one million livestock, exposed 1.7 million people to moderate and acute malnutrition, and affected the livelihoods of about 10 million people (Philip et al., 2018). However, the drought did not cause an increase in the rates of chronic and acute child malnutrition, though the rates of acute malnutrition did increase in areas with poor road access (Hirvonen et al., 2020).

\subsection{Agricultural production diversity, food security and child malnutrition}

Because of the important role of agriculture in providing food and income for rural farmers, household agricultural production has the potential to promote food security and improve nutrition. The commonly agreed upon pathways through which agriculture affects food security and child malnutrition can be summarized as follows (Carletto et al., 2015; Gillespie \& van den Bold, 2017; Ruel et al., 2013):

1. Agriculture as a source of food: increases in the amount and diversity of food produced on the farm translate into more food available for household consumption.

2. Agriculture as a source of income: income generated from agricultural activities can be used to purchase food and non-food items and invest in education and health, which can improve people's diets and overall well-being.

3. Agricultural production can affect food prices, with implications for households' purchasing capacity and net selling households: an increase in prices would benefit net sellers and bring them additional profits but can negatively impact poor households who buy food; decreasing prices can be beneficial for those who purchase food but detrimental to net sellers.

4. Agriculture and the role and women: women's involvement in agricultural work may affect intra-household allocation of resources and decision-making, with implications for women's own health and children's nutrition.

\footnotetext{
${ }^{1}$ There are multiple categories of droughts. A meteorological drought is defined as rainfall deficit in an area during a period of time. Rainfall deficit can be expressed in relation to monthly/yearly/long-term and other averages, cumulative shortages, etc. See Mishra and Singh (2010) for a review of drought concepts.
}

In line with the focus on nutritionally sensitive agriculture discussed above, many studies that investigate the relationship between household-level agriculture and food security have been conducted with attention to agricultural production diversity. Agricultural production diversity can be measured in different ways, but the general idea is to quantify the diversity of food or crop/livestock species produced on the farm. Briefly, in the current literature agricultural production diversity has been represented by 1) counts of all crop and/or livestock species produced on a farm (Dillon et al., 2015; Islam et al., 2018; Jones, 2017b; Koppmair et al., 2017; Shively \& Sununtnasuk, 2015); 2) the number of food groups produced by the household that contribute to the Household Dietary Diversity Score (HDDS) ${ }^{2}$ (Hirvonen et al., 2018; Koppmair et al., 2017; Kumar et al., 2015); 3) Margalef species richness index that factors in farm area cultivated by various crops but does not account for livestock ownership and production of meat, dairy, and eggs (Islam et al., 2018; Sibhatu et al., 2015); 4) the absolute number or proportion of crops in specific crop groups (e.g., cereal, tubers, pulses, etc.) (Hirvonen \& Hoddinott, 2017; Muller, 2009; Shively \& Sununtnasuk, 2015); 5) village-level crop diversity (Tobin et al., 2019; Remans et al., 2011).

\subsubsection{Crop diversity}

As can be seen from the pathways between agriculture and food security and nutrition described above, increasing the amount and diversity of food on the farm can have direct implications for household income, food security, and, consequently, child nutrition. Increasing the number of cultivated crops may improve child nutrition because a more diverse portfolio of grown crops can lead to higher income and improved consumption (Chegere \& Stage, 2020; Dillon et al., 2015; Hirvonen \& Hoddinott, 2017; Jones, 2017a, 2017b; Jones et al., 2014; Koppmair et al., 2017; Kumar et al., 2015; Muller, 2009; Shively \& Sununtnasuk, 2015; Sibhatu et al., 2015; Sibhatu \& Qaim, 2018). Crops have different nutritional value and micronutrient contents, so increasing the number of cultivated crops may improve diet quality. In addition, a greater number of cultivated crops can protect household food production and income from weather shocks in the context of rainfed agriculture because different crops have different sensitivity to temperature and rainfall levels.

\footnotetext{
${ }^{2}$ HDDS reflects the number of food groups (out of 12 possible food groups) a household has consumed over the last $24 \mathrm{~h}$, although some studies use a 7-day recall (recall time period is driven by the way survey questions are asked) (Swindale \& Bilinsky, 2006).
} 


\subsubsection{Livestock diversity}

Another important aspect of household agriculture - livestock ownership - has generally shown a positive relationship with household-level food security and child nutrition (Abafita \& Kim, 2014; Azzarri et al., 2014; Belachew et al., 2012; Beyene \& Muche, 2010; Bogale \& Shimelis, 2009; Demeke et al., 2011; Hoddinott et al., 2015; Shively \& Sununtnasuk, 2015; Slavchevska, 2015). Not only are livestock important sources of animal protein via meat, dairy, and egg production, which stimulates linear growth and can prevent micronutrient deficiencies (Neumann et al., 2002), but larger livestock (e.g., oxen) also aid in land cultivation by providing a source of draft power and manure (Sansoucy, 1995). Evidence from Ethiopia, for example, indicates that the profits from the sale of animal products allow households to increase their dietary diversity (Ayele \& Peacock, 2003; Beyero et al., 2015; Okike et al., 2005). The diversity of animals on the farm may relate to child nutrition via different pathways. For example, sheep and goats can be beneficial to child nutrition as they provide a cheap and readily available source of animal protein: sheep and goats require little feed, are more easily managed than cows and oxen, can quickly adapt to adverse environmental conditions, and their meat and milk can be stored without refrigeration because of their small size (Devendra, 2005; Workneh et al., 2003), which is particularly advantageous in the face of low electrification in Ethiopia. Cows and oxen, on the other hand, are more expensive to rear, but are useful for land cultivation as a source of draft power and manure (Sansoucy, 1995), which can promote crop growth, improve yields and, consequently, reduce child malnutrition. It is important to note that livestock ownership can also present a health hazard and result into diarrhea and environmental enteric disorder in children that occur via exposure to animal feces and pathogens. This is a rather understudied research area, but empirical evidence from Ethiopia and other lowincome countries indicates that exposure to livestock, and particularly poultry, can decrease child height-for-age z-scores (Headey et al., 2017; Headey \& Hirvonen, 2016).

\subsubsection{Household- and village-level agricultural production diversity}

Recent research has also called for considering agricultural diversity at scales beyond an individual household - such as at landscape and district - to highlight that commercial agriculture in low-resource settings may disadvantage local households because of the incentives to export locallyproduced nutritious foods and to import processed foods (Remans et al., 2015). In addition, district- or village-level production diversity may be directly related to household food security and child malnutrition as most small-scale farmers buy at least some food from the market and do not solely rely on their own farm-produced food (Frelat et al., 2016; Sibhatu et al., 2015). Therefore, considering agricultural diversity at the village-level may be helpful for understanding how broader economic and environmental factors shape villagelevel agriculture, and how that in turns relates to child malnutrition. Few examples of considering village-level crop diversity include Tobin et al. (2019) and Remans et al. (2011), both of which showed a positive relationship between village-level crop diversity and nutritional outcomes. Still, the consideration of multiple scales is not routinely done in studies that evaluate the relationship between agricultural production diversity and dietary and nutritional outcomes.

In sum, recent empirical studies show that farm diversity can improve individual and household-level nutrition and diets, although the impacts are not large and can be mediated by a variety of factors such as market transactions (Hirvonen \& Hoddinott, 2017; Hoddinott et al., 2015; Koppmair et al., 2017; Sibhatu et al., 2015), gender, wealth, intra-household food allocation, as well as farm-level use of inputs such as fertilizer, improved crop varieties, and irrigation (Koppmair et al., 2017; Shively \& Sununtnasuk, 2015). For example, Hoddinott et al. (2015) showed that the positive effect of livestock ownership on children's linear growth in rural Ethiopia can be substituted by a market in the area. In some cases, high agricultural production diversity may be detrimental to household income and, consequently, food security and nutrition if households produce many crop species instead of specializing in fewer crops that could generate the most income (Sibhatu et al., 2015).

\section{Data}

\subsection{Sociodemographic and agricultural data and measures}

This study relies on the 2011-2012 (wave 1), 2013-2014 (wave 2), and 2015-2016 (wave 3) rounds of the Ethiopia Socioeconomic Survey (ESS) collected in a collaborative effort by the World Bank Living Standards Measurement Study (LSMS) and the Central Statistics Agency of Ethiopia (CSA $\&$ World Bank, 2017). The Ethiopia LSMS was conducted by the World Bank within its Integrated Surveys on Agriculture (LSMS-ISA). The surveys include about 4000 households that were tracked between the waves. The first survey, in 2011, only surveyed households in rural areas, but starting in 2013 the sampling frame was extended to include rural and urban households. The surveys are representative at the level of the four most populous regions - Amhara, Oromia, Tigray, and Southern Nations, Nationalities, and People's region (SNNP). The collected data include demographic characteristics and such domains as health, agriculture, time use and labor, food security and shocks, and banking and credit. 
These data are georeferenced at the level of enumeration areas (EA) - roughly village level - with displacement: in public files locations of EAs are displaced up to $2 \mathrm{~km}$ in urban areas, up to $5 \mathrm{~km}$ in rural areas, and a $1 \%$ random sample of EAs is displaced up to $10 \mathrm{~km}$. The raw microdata were obtained through the World Bank (CSA \& World Bank, 2017). Figure 1 depicts the location of enumeration areas from the survey.

There are two outcome measures in the study: height-for-age (HAZ) and weight-for-height (WHZ) z-scores. To compute zscores we used anthropometric measurements from the LSMS household questionnaires and the 2006 WHO growth reference standards using the "antro" package from the R Environment for Statistical Computing (R Core Team, 2019; Schumacher, 2020). In our statistical analysis, we used continuous z-scores as opposed to binary indicators of stunting/wasting to prevent the loss of information when converting continuous measurements to binary indicators. In line with previous work, we excluded implausibly high and low z-scores with values above +6 and below -6 (Hoddinott et al., 2015).

To ensure consistency in units and measurement across years, we extracted several measures form the LSMS data distributed by the University of Washington's Evans School Policy Analysis \& Research Group (EPAR). EPAR relies on the same LSMS data used in this study to produce agricultural indicators comparable across time and countries (EPAR, 2019). We relied on the EPAR's measures of household non-farm income (income from non-farm sources), farm area, and the proportion of livestock products value sold. Household income and farm area, along with other agricultural characteristics, are notoriously challenging to measure (Carletto \& Gourlay, 2019; Lobell et al., 2019), which is why we extracted those measures from the research group specializing in producing comparable indicators.

\subsubsection{Agricultural production diversity: Farm production diversity}

From the LSMS questionnaires, we created key measures of interest that describe agricultural production diversity - farm production diversity and farm production composition (Table 1). Farm production diversity was computed as the number of food groups produced by the household that contribute to Household Dietary Diversity Score (HDDS). The HDDS is comprised of the following 12 food groups: cereals; tubers and root crops; vegetables; fruits; meat; eggs; fish; beans; milk and milk products; oils and fats; sweets; spices, condiments, and beverages. Because our primary interest is in farm-level contribution to child nutrition via food production, in line with previous research (Hirvonen et al., 2018;

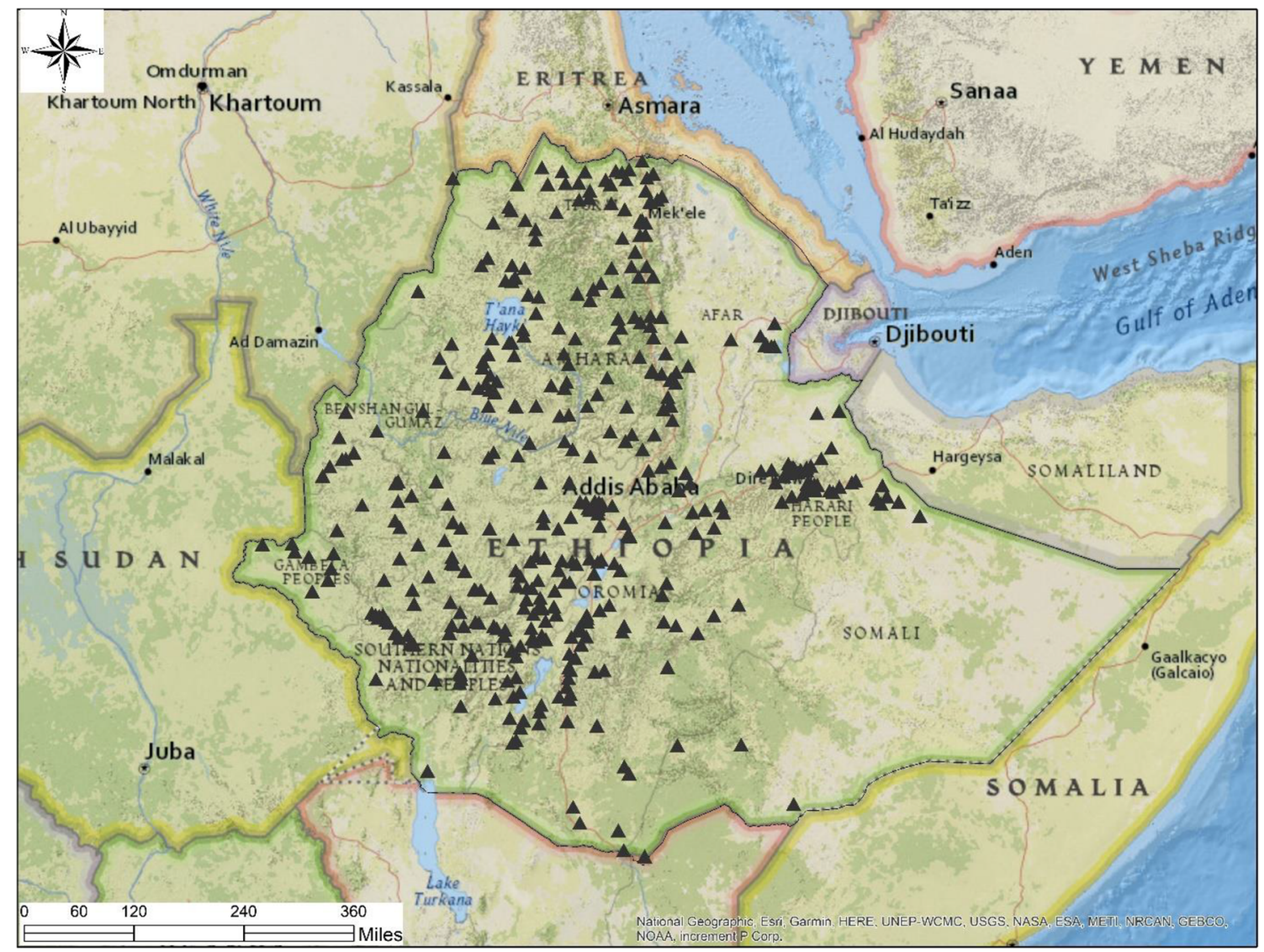

Fig. 1 Location of the Ethiopia living standards measurement study enumeration areas (black triangles). This figure was created in ArcGIS 
Table 1 Summary statistics from the Ethiopia Living Standards Measurement Study

\begin{tabular}{|c|c|c|c|c|c|c|}
\hline \multirow{2}{*}{$\begin{array}{l}\text { Ethiopia LSMS sample } \\
\text { Variable name }\end{array}$} & \multicolumn{2}{|c|}{$2011-12$} & \multicolumn{2}{|c|}{$2013-14$} & \multicolumn{2}{|c|}{$2015-16$} \\
\hline & Mean & SD & Mean & SD & Mean & SD \\
\hline \multicolumn{7}{|l|}{ Outcome variables } \\
\hline Child's HAZ & -1.668 & 1.923 & -1.508 & 1.882 & -1.410 & 2.063 \\
\hline Child's WHZ & -0.392 & 1.453 & -0.303 & 1.484 & -0.286 & 1.566 \\
\hline \multicolumn{7}{|l|}{ Explanatory variables } \\
\hline \multicolumn{7}{|l|}{ Household characteristics } \\
\hline Age of hh head (years) & 38.340 & 11.410 & 39.260 & 11.820 & 40.340 & 11.600 \\
\hline Female-headed household (1/0) & 0.121 & & 0.151 & & 0.164 & \\
\hline Household size (persons) & 6.074 & 2.130 & 5.973 & 2.171 & 6.135 & 2.122 \\
\hline Dependency ratio & 0.853 & 0.769 & 1.527 & 0.963 & 1.524 & 0.897 \\
\hline Mother has any education $(1 / 0)$ & 0.261 & & 0.380 & & 0.416 & \\
\hline Floor type (finished) & 0.030 & & 0.120 & & 0.143 & \\
\hline Source of drinking (protected) & 0.493 & & 0.627 & & 0.712 & \\
\hline Household uses a toilet $(1 / 0)$ & 0.506 & & 0.619 & & 0.665 & \\
\hline Non-farm income (PPP \$2016) ${ }^{1}$ & 3441 & 8859 & 5144 & 13,517 & 9966 & 21,851 \\
\hline Farm area (ha) & 0.921 & 4.588 & 0.917 & 2.917 & 1.143 & 9.638 \\
\hline Share of livestock products value sold & 0.219 & 0.291 & 0.234 & 0.282 & 0.153 & 0.269 \\
\hline \multicolumn{7}{|l|}{ Farm production diversity (household-level) } \\
\hline Number of food groups produced by the farm & 1.834 & 1.345 & 3.183 & 2.136 & 3.660 & 2.356 \\
\hline \multicolumn{7}{|l|}{ Farm production composition (household-level) } \\
\hline Cereals (share) $)^{2}$ & 0.683 & 0.359 & 0.531 & 0.323 & 0.519 & 0.328 \\
\hline Roots (share) & 0.026 & 0.099 & 0.126 & 0.195 & 0.130 & 0.202 \\
\hline Pulses (share) & 0.251 & 0.333 & 0.140 & 0.177 & 0.137 & 0.177 \\
\hline Fruit (share) & 0.022 & 0.098 & 0.118 & 0.194 & 0.136 & 0.204 \\
\hline Vegetables (share) & 0.019 & 0.083 & 0.085 & 0.150 & 0.079 & 0.145 \\
\hline Household produces meat (1/0) & 0.453 & & 0.702 & & 0.761 & \\
\hline Household produces dairy (1/0) & 0.226 & & 0.596 & & 0.676 & \\
\hline Household produces eggs (1/0) & 0.391 & & 0.393 & & 0.425 & \\
\hline \multicolumn{7}{|l|}{ Child characteristics } \\
\hline Child's age (months) & 32.52 & 14.68 & 32.75 & 15.03 & 33.24 & 15.18 \\
\hline Child's sex (1=female) & 0.484 & & 0.493 & & 0.482 & \\
\hline \multicolumn{7}{|l|}{ Climatic conditions } \\
\hline 12-month rainfall anomaly (z-score $)^{3}$ & 0.080 & & 0.499 & 0.867 & -0.931 & 1.146 \\
\hline $\mathrm{N}$ (children) & 2217 & & 2413 & & 2172 & \\
\hline
\end{tabular}

SD refers to standard deviation

${ }^{1}$ PPP \$ refers to the international dollars in 2016. The University of Washington's Evans School of Public Policy converts local currencies to international dollars using the private consumption purchasing power parity (PPP) conversion factor and the Gross Domestic Product PPP conversion factor from the World Bank International Comparison Program

${ }^{2}$ Share refers to the proportion of crops belonging to a particular crop group (cereal, roots, pulses, fruit, or vegetables) relative to all food crops cultivated by the household

${ }^{3}$ Rainfall anomaly z-scores were computed using the following formula (example for the 2015-16 LSMS survey): $z_{\text {rainfall }}=\frac{\sum_{\text {rainfall }}^{\text {Feb 2015-Jan 2016 }}-\text { Average total rainfall }_{F e b-J a n,}, \quad 1981-2016}{\text { dd (Total rainfall }}$

Koppmair et al., 2017) we focused on these food groups produced by the household: cereals; tubers and root crops; vegetables; fruits; meat; eggs; beans; milk and milk products. In other words, we excluded oils and fats; sweets; spices, condiments, and beverages because they do not provide much nutritional value. We did not include fish because there was no data on household fish farming. In addition to household-level, we also computed a village-level 
measure of farm production diversity as an average of the number of food groups produced by the households residing in the village (Table 2).

\subsubsection{Agricultural production diversity: Farm production composition}

The measure of farm production composition is designed to complement the farm production diversity measure and to shed more light on the relative contribution of various crop and animal products to household diets, food security, and, consequently, child malnutrition. We created the following measures to describe farm crop production composition: shares of 1) cereal, 2) root, 3) pulses, 4) fruit, and 5) vegetable crops among all food crops cultivated by the household. Shares reflect the proportion of crop varieties belonging to a particular crop group (cereal, roots, pulses, fruit, or vegetables) relative to the number of all food crop varieties cultivated by the household. For example, if a household cultivates a total of 15 food crops, 5 varieties of which are cereal crops, the share of cereal crop equals $5 / 15 \approx 0.33$ (or roughly $33 \%$ ). On the animal products side, we created variables indicating whether a household owns meat-, dairy-, and egg-producing livestock. It is important to note that one animal can contribute to more than one indicator variables: a hen can lay eggs and be a source of meat. We also computed these measures (expressed as proportions of households cultivating specific crop groups and producing dairy, meat, and eggs) at the level of villages (Table 2).

\subsection{Environmental data and measures}

In this study we investigated how exposure to suboptimal rainfall might modify the relationship between agricultural production diversity and child malnutrition, given that 1) poor rainfall has a long history of undermining Ethiopia's agriculture (Devereux \& Sussex, 2000), and 2) Ethiopia experienced a meteorological drought that overlapped with the 2015-16 survey (Philip et al., 2018). We relied on the Climate Hazards Group InfraRed Precipitation with Station data (CHIRPS) as a source of rainfall data. CHIRPS provide quasi-global rainfall data at a high spatial $\left(0.05^{\circ}\right.$ or $\sim 5 \mathrm{~km}$ at the equator) and temporal (daily, pentadal, and monthly) resolution from 1981 onward in close to real time (Funk et al., 2015). The dataset was developed by the Climate Hazards Group at the University of California Santa Barbara to support the United States Agency for International Development Famine Early Warning Systems Network (FEWS NET). Input data to produce CHIRPS include satellite estimates and weather data from stations (Funk et al., 2015). To measure suboptimal rainfall we first computed z-scores of total rainfall anomalies for the 12-month periods preceding each survey using the georeferenced location of LSMS enumeration areas (EA), which roughly represent villages. Household data were collected during February-April for every survey year, after the households had planted and started harvesting their crops, and the 12-month rainfall anomalies characterize growing season conditions relevant for crop cultivation. We computed the anomalies (z-scores) using the following formula (example for the 2015-16 rainfall anomaly z-score):

Table 2 Summary statistics for the village-level measures of agricultural production diversity from the Ethiopia Living Standards Measurement Study

\begin{tabular}{|c|c|c|c|c|c|c|}
\hline \multirow[t]{2}{*}{ Ethiopia LSMS sample } & \multicolumn{2}{|c|}{$2011-12$} & \multicolumn{2}{|c|}{$2013-14$} & \multicolumn{2}{|c|}{$2015-16$} \\
\hline & Mean & SD & Mean & SD & Mean & SD \\
\hline \multicolumn{7}{|l|}{ Village production diversity } \\
\hline Average number of food groups produced by the households in the village & 1.797 & 1.124 & 2.834 & 2.003 & 3.338 & 2.273 \\
\hline \multicolumn{7}{|l|}{ Village production composition } \\
\hline Cereals (share) ${ }^{1}$ & 0.712 & 0.244 & 0.552 & 0.293 & 0.519 & 0.276 \\
\hline Roots (share) & 0.021 & 0.077 & 0.110 & 0.160 & 0.119 & 0.168 \\
\hline Pulses (share) & 0.228 & 0.206 & 0.135 & 0.149 & 0.137 & 0.136 \\
\hline Fruit (share) & 0.018 & 0.074 & 0.120 & 0.175 & 0.137 & 0.157 \\
\hline Vegetables (share) & 0.020 & 0.083 & 0.083 & 0.114 & 0.088 & 0.133 \\
\hline Proportion of village households that produce meat & 0.429 & 0.455 & 0.633 & 0.408 & 0.696 & 0.411 \\
\hline Proportion of village households that produce dairy & 0.199 & 0.314 & 0.194 & 0.320 & 0.605 & 0.415 \\
\hline Proportion of village households that produce eggs & 0.376 & 0.326 & 0.356 & 0.349 & 0.394 & 0.384 \\
\hline N (villages/LSMS Enumeration Areas) & 312 & & 416 & & 410 & \\
\hline
\end{tabular}

SD refers to standard deviation

${ }^{1}$ Share refers to the average proportion of crops belonging to a particular crop group (cereal, roots, pulses, fruit, or vegetables) relative to all food crops cultivated by the households in the village. The variable is computed by averaging the number of crops in a specific group produced by all the households in the village 


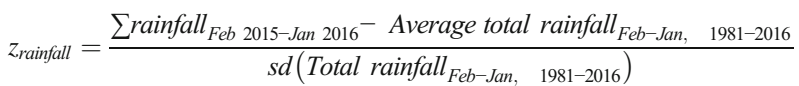

After computing z-scores, we created an indicator variable for children residing in areas that experienced rainfall anomalies less than -2 SD below the long-term average (Hirvonen et al., 2020). Summary statistics for the variables used in the analysis can be found in Tables 1 and 2 .

\section{Methods}

This study takes advantage of the longitudinal structure of the data and combines all children surveyed in 2011, 2013 and 2015 to create a longitudinal dataset. We do not limit the sample to the children observed in every survey (i.e. three times) but include all children with plausible $\mathrm{z}$ scores, thus having an unbalanced panel of 6214 children-years. A total of 890 children from the 2011 survey round were re-interviewed in 2013 (or $40 \%$ of the children interviewed in 2011); 1195 children from the 2013 round $(50 \%)$ were also interviewed in 2015; 201 children $(9 \%)$ were interviewed in all three rounds. This attrition is indicative of children "aging out" of sample and becoming ineligible for inclusion in the survey - age eligibility for children is capped at 59 months. Descriptive statistics (Tables 1 and 2) reveal that farm production diversity and farm production composition are dynamic and change from 2011 to 2013 to 2015 . We take advantage of the variation in these farm production diversity measures to investigate their relationship with child HAZ and WHZ. To do so, we estimate longitudinal models of child HAZ and WHZ with fixed effects for each child and year of survey. The longitudinal fixed effects models rely on the within-child variation in HAZ and WHZ from 2011 to 2013 to 2015. The estimated coefficient of variable $X$ denotes how much the outcome $\mathrm{Y}$ changes over time, on average per child, when $\mathrm{X}$ goes up by one unit (TorresReyna, 2010). The fixed effects models control for stable, time-invariant characteristics even if they are not included in the models because, by virtue of repeated observations for children, children serve as their own controls (TorresReyna, 2007). This feature of the longitudinal fixed effects framework is advantageous for the analysis of child malnutrition since the available variables collected in the survey cannot account for all the time-invariant factors associated with child malnutrition (Hsiao, 2007).

Informed by prior research (Brown et al., 2020; Shively \& Sununtnasuk, 2015; Sibhatu \& Qaim, 2018), these models (Eq. 1) control for the following household and child characteristics that may impact child HAZ and WHZ: child age, child age squared, child sex; age and sex of household head; household size; dependency ratio (the ratio of the number of household members $0-14$ years and 65 and older to the number of household members of working age (15-64)); child mother's education; whether a household has a protected drinking water source, finished floor, and uses a toilet; farm area; and non-farm income (logged).

$$
\left(Y_{i t}\right)=\beta_{0}+\beta \operatorname{SocDem}_{i t}+\gamma A g \operatorname{Div}_{i t}+\alpha_{i}+\delta_{t}+\varepsilon_{i t}
$$

In Eq. 1, $Y_{i t}$ represents a continuous measure of HAZ or WHZ of child $i$ at time $t$. SocDem ${ }_{i t}$ represent child- and household sociodemographic characteristics for child $i$ at time $t$; $A g D i v_{i t}$ represent household farm production or farm production composition measures. Child-specific unknown intercepts are denoted by $\alpha_{i} ; \delta_{t}$ are time fixed effects; $\varepsilon_{i t}$ is the error term. To account for the data structure wherein the weather measures are constructed at the level of enumeration areas, we cluster standard errors at the level of enumeration areas. We estimated these models for entire sample of children (659 months old). We also estimated separate models for $6-$ 23 month-old children and 24-59 month-old children to account for that the fact that most growth faltering occurs within the first 24 months of life (Victora et al., 2010). However, the estimates from the subsample of 6-23-month-old children were unreliable, hence here we present results estimated on the full sample of children. Results from the models estimated with the full sample did not differ qualitatively from the results from a sample of children 24-59-month-old. Estimation was done using the "plm" package of the R environment for statistical computing (Croissant \& Millo, 2008).

In addition to using farm-level measures of production diversity and composition, we also estimated the same models with village-level measures of agricultural production diversity and composition. We computed Variance Inflation Factors (VIFs) to check for multicollinearity among the independent variables; the VIFs for all the variables except child age and child age squared did not exceed 4 , thus indicating no problem of multicollinearity. The high VIFs for child age and child age squared (both VIFs $=\sim 24$ ) do not present a problem because they represent structural collinearity caused by using an original variable (child age) and its squared version (child age squared) in the models.

In a secondary analysis, we also estimate a set of OLS models for the subsample of children who were exposed to rainfall deficits. To identify such children, we limit the total sample $(N=6214)$ to children residing in areas where rainfall in the 12-month period preceding the survey was more than -2 standard deviations below the long-term 1981-2016 average (Hirvonen et al., 2020). Such children $(N=583)$ were observed in the survey once, thus we estimate OLS regressions for child HAZ and WHZ for this subsample of children and use the same independent variables as in Eq. 1. 


\section{Results}

\subsection{Farm production diversity, farm production composition and child height-for-age}

Table 3 present results from the longitudinal models estimating associations among farm production diversity and child heightfor-age. Adjusted for the child biological and household-level sociodemographic characteristics, farm production diversity shows a significant positive association with child HAZ. An increase in farm production diversity by one food group is associated with a 0.2 -unit increase in child height-for-age z-score.

Models include child and time fixed effects. Standard errors (SE) are clustered at the village (EA) level.

To describe what farm products - specific crop types and animal products - are beneficial for child HAZ, we now turn to Table 4. Cultivating more cereal and root crops relative to other crop groups is associated with an increase in HAZ. In addition, we observe significant positive associations between household production of animal products and HAZ: children from households that produce dairy have a 0.6-unit higher HAZ, on average, compared to children from non-dairy producing households. We do not observe significant associations between farm production diversity, farm production composition, and a second outcome of interest - child WHZ (Tables S2 and S3 in the Supplementary Material).

Table 3 Results from the longitudinal fixed effects models estimating an association between child HAZ and farm production diversity

\begin{tabular}{llll}
\hline Variable & $\mathrm{b}$ & $\mathrm{SE}$ & sig \\
\hline Child characteristics & & & \\
Child age (months) & -0.056 & 0.011 & $* * *$ \\
Child age squared (months) & 0.001 & 0.001 & $* * *$ \\
Child sex (female) & 0.790 & 0.262 & $* *$ \\
Household sociodemographic characteristics & & & \\
Age of hh head (years) & -0.008 & 0.010 & \\
Female-headed household & -0.254 & 0.224 & \\
Household size & 0.061 & 0.048 & \\
Dependency ratio & 0.161 & 0.069 & $*$ \\
Mother has any education & 0.096 & 0.169 & \\
Household uses a toilet & 0.001 & 0.112 & \\
Water source (protected) & 0.187 & 0.129 & \\
Floor type (finished) & 0.496 & 0.375 & \\
Farm size (ha) & 0.004 & 0.013 & \\
Log (non-farm income, PPP \$2016) & -0.016 & 0.012 & \\
Farm production diversity & & & \\
Farm production diversity & 0.176 & 0.035 & $* * *$ \\
$\mathrm{R}^{2}$ & 0.049 & & \\
N (children-years) & 6214 & & \\
\hline
\end{tabular}

$* p<0.05 * * p<0.01 * * * \mathrm{p}<0.001$
Table 4 Results from the longitudinal fixed effects models estimating an association between child HAZ and farm production composition

\begin{tabular}{llll}
\hline Variable & $\mathrm{b}$ & $\mathrm{SE}$ & $\mathrm{sig}$ \\
\hline Farm production composition & & & \\
Cereals (share) & 0.501 & 0.169 & $* *$ \\
Roots (share) & 1.304 & 0.323 & $* * *$ \\
Pulses (share) & 0.171 & 0.245 & \\
Vegetables (share) & 0.436 & 0.348 & \\
Fruit (share) & 0.529 & 0.348 & \\
Household produces meat & 0.289 & 0.127 & $*$ \\
Household produces dairy & 0.592 & 0.114 & $* * *$ \\
Household produces eggs & 0.022 & 0.110 & \\
$\mathrm{R}^{2}$ & 0.068 & & \\
$\mathrm{~N}$ (children-years) & 6214 & & \\
\hline
\end{tabular}

$* p<0.05 * * p<0.01 * * * p<0.001$

Models include child-level and time fixed effects. Standard errors (SE) are clustered at the village (EA) level. The models are adjusted for the child and household sociodemographic characteristics (not shown for brevity). Full model results can be found in the Supplementary Material (Table S1)

To consider an alternative scale in the measures of production diversity, we re-estimated the models using the villagelevel measures of farm production diversity and production composition. The results are in line with those using farmlevel measures (Tables S4-S7 in the Supplementary Material), suggesting that the diversity of foods produced in the households' community and not only household's own production might impact household food security and, consequently, child malnutrition.

\subsection{The role of infrastructure and agricultural technologies}

Previous studies reported effect modification of child growth by infrastructure (such as roads and markets in the area) and technology adoption by households (use of improved seeds, application of inorganic fertilizer, etc.) (Hoddinott et al., 2015; Koppmair et al., 2017; Shively, 2017). To test whether the associations between farm production diversity and HAZ/ WHZ are modified by the infrastructure in the area and technology adoption, we interacted the farm diversity variable and the relative measures of farm production composition (shares of specific crops and household production of meat $/ \mathrm{milk} /$ eggs) with the following variables: distance to the nearest major road; presence of a large weekly market in an area; distance to the nearest market; household use of irrigation; household rate of application of inorganic fertilizer; household use of improved seeds. We did not observe statistically significant interactions between these measures and the measures of farm diversity. 


\subsection{Rainfall conditions in the 2015-16 growing season and child height-for-age}

In 2015 central and northeastern regions of Ethiopia experienced suboptimal rainfall (Philip et al., 2018). To explore whether diminished rainfall in 2015 modified the relationship between farm production diversity and child malnutrition, we estimated longitudinal fixed effects models with an interaction term between farm production diversity and an indicator whether children were exposed to rainfall anomalies of more than -2 SD below the long-term (1981-2016) average. The interaction was statistically significant - Fig. 2 demonstrates that, while farm production diversity is positively associated with child HAZ for children living in areas with normal rainfall, the slope is much steeper and negative for children residing in areas that received less rainfall than usual. In other words, for children who were exposed to suboptimal rainfall, an increase in farm production diversity was negatively associated with height-for-age z-scores. We did not observe any statistically significant interactions between suboptimal rainfall and measures reflecting farm production composition (shares of specific crops and household production of meat/milk/eggs). We also did not observe a statistically significant interaction for child WHZ. The interaction effect between village-level farm production diversity and rainfall deficit exposure showed the same negative relationship with HAZ as the household-level measure.

To further explore how the relationship between farm production diversity and child malnutrition may depend on the prevailing rainfall conditions, we repeated the analyses for the subsample of children who resided in areas with rainfall anomalies more than $-2 \mathrm{SD}$ below the long-term average (Tables 5 and 6 for HAZ; Tables S9 and S10 in the Supplementary Material for WHZ). It is worth noting that such children were only observed once, during the 2015-16 survey, so the following results are from the OLS regressions.
Table 5 Results from the OLS models estimating an association between child HAZ and farm production diversity for the subsample of children exposed rainfall anomalies less than -2 SD relative to the longterm average

\begin{tabular}{llll}
\hline Variable & $\mathrm{b}$ & $\mathrm{SE}$ & sig \\
\hline Child characteristics & & & \\
Child age (months) & -0.054 & 0.024 & $*$ \\
Child age squared (months) & 0.001 & 0.001 & \\
Child sex (female) & 0.093 & 0.171 & \\
Household sociodemographic characteristics & & \\
Age of hh head (years) & 0.005 & 0.007 & \\
Female-headed household & -0.230 & 0.210 \\
Household size & 0.019 & 0.036 \\
Dependency ratio & 0.084 & 0.139 & \\
Mother has any education & 0.244 & 0.213 & \\
Household uses a toilet & -0.189 & 0.185 & \\
Water source (protected) & 0.124 & 0.222 & \\
Floor type (finished) & 0.583 & 0.262 & $*$ \\
Farm size (ha) & -0.068 & 0.059 & \\
Log (non-farm income, PPP $\$ 2016)$ & -0.037 & 0.023 \\
Farm production diversity & & \\
Farm production diversity & -0.124 & 0.048 \\
$\mathrm{R}^{2}$ & 0.087 & \\
N (children) & 583 & \\
\hline
\end{tabular}

$* p<0.05 * * p<0.01 * * * p<0.001$

Standard errors (SE) are clustered at the village (EA) level

Similar to the results from the model with an interaction between suboptimal rainfall and dietary diversity, for children exposed to suboptimal rainfall the association between farm production diversity and child HAZ becomes negative (Table 5). When we investigate specific crops types and animal products for the exposed children (Table 6), two
Fig. 2 Interaction effect between household farm production diversity and rainfall conditions on child height-for-age z-scores. This and all the following figures were created in $R$

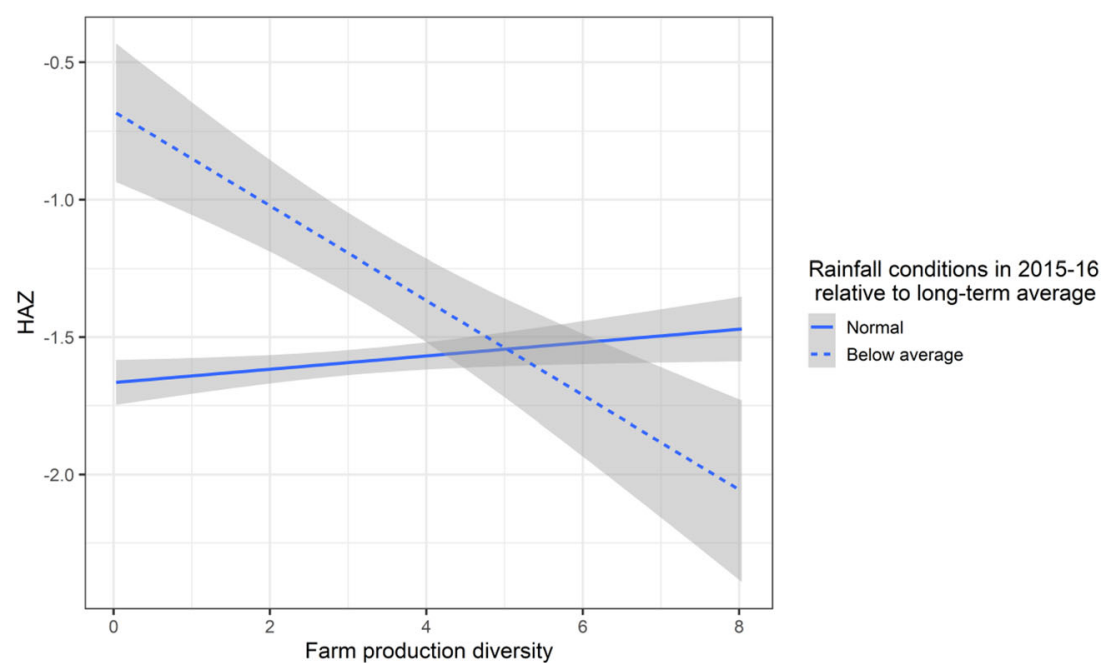


Table 6 Results from the OLS models estimating an association between child HAZ and farm production composition for the subsample of children exposed rainfall anomalies less than $-2 \mathrm{SD}$ relative to the long-term average

\begin{tabular}{llll}
\hline Variable & $\mathrm{b}$ & $\mathrm{SE}$ & $\mathrm{sig}$ \\
\hline Farm production composition & & & \\
Cereals (share) & 0.243 & 0.378 & \\
Roots (share) & -1.585 & 1.081 & \\
Pulses (share) & -2.081 & 0.624 & $* * *$ \\
Vegetables (share) & -0.381 & 1.026 & \\
Fruit (share) & 0.595 & 0.529 & \\
Household produces meat & -0.441 & 0.539 & \\
Household produces dairy & 0.489 & 0.377 & \\
Household produces eggs & -0.153 & 0.219 & \\
$\mathrm{R}^{2}$ & 0.120 & & \\
$\mathrm{~N}$ (children) & 583 & & \\
\hline
\end{tabular}

$* p<0.05 * * p<0.01 * * * p<0.001$

Standard errors (SE) are clustered at the village (EA) level

observations stand out. First, household production of dairy is no longer significantly associated with child HAZ. Second, the share of pulses relative to other crops is associated with decreases in HAZ. We observed a statistically significant association for the WHZ of the exposed children: children from meat-producing households had WHZ -0.66 units lower compared to children whose households did not produce meat (Table S10 in the Supplementary Material).

While a relatively small number of children were exposed to suboptimal rainfall $(N=583)$, these findings nevertheless warrant further investigations into the specific mechanisms connecting farm production diversity and children nutrition. If households cultivate too many crops, they may lose out on benefits from specializing in fewer but more expensive and/or nutritious crops. We speculate that investing in a more diverse crop portfolio during suboptimal rainfall conditions may be detrimental to child nutrition because of diminished food security and changes in childcare practices and discuss this further in the next section. It does not appear that the droughtexposed households cultivated fewer crop varieties than the non-exposed according to a two-sided t-test $(p$ value $=0.05$ ) In addition, both groups of households grew roughly equal shares of cereal crops, but unexposed households grew more roots, pulses, and vegetables.

It is interesting that the measures describing household livestock ownership lose their statistical significance in the models for the subsample of exposed children (recall, household production of dairy and eggs showed a positive association with child HAZ for the full sample). Households may sell or slaughter livestock to make up for crop yields damaged by the droughts, which can allow them to maintain an optimal level of food consumption (Hoddinott \& Kinsey, 2001). Indeed, exposed households sell about $\sim 5 \%$ more livestock products than their non-exposed counterparts $(p=0.02)$. Moreover, when we interact farm production diversity and the share of livestock product sold for the exposed children, we observe a steeper (negative) slope for households that sell less of their livestock products (Fig. 3). This means that at the mean level of farm production diversity, children from households that sell a larger share of animal products have smaller decreases in HAZ compared to children whose households sell less livestock.

\subsection{Limitations}

Even though we relied on the longitudinal data including repeated observation for children and this exploited within-child variation in child HAZ, we still cannot claim our findings as causal as ours is not a balanced panel where every child was observed exactly three times. In principle, more frequently repeated surveys are needed to accurately evaluate causal relationships between farm production diversity and child
Fig. 3 Interaction effect between household farm production diversity and the share of livestock products sold (by value) on height-for-age z-scores for children exposed to suboptimal rainfall in 2015-16

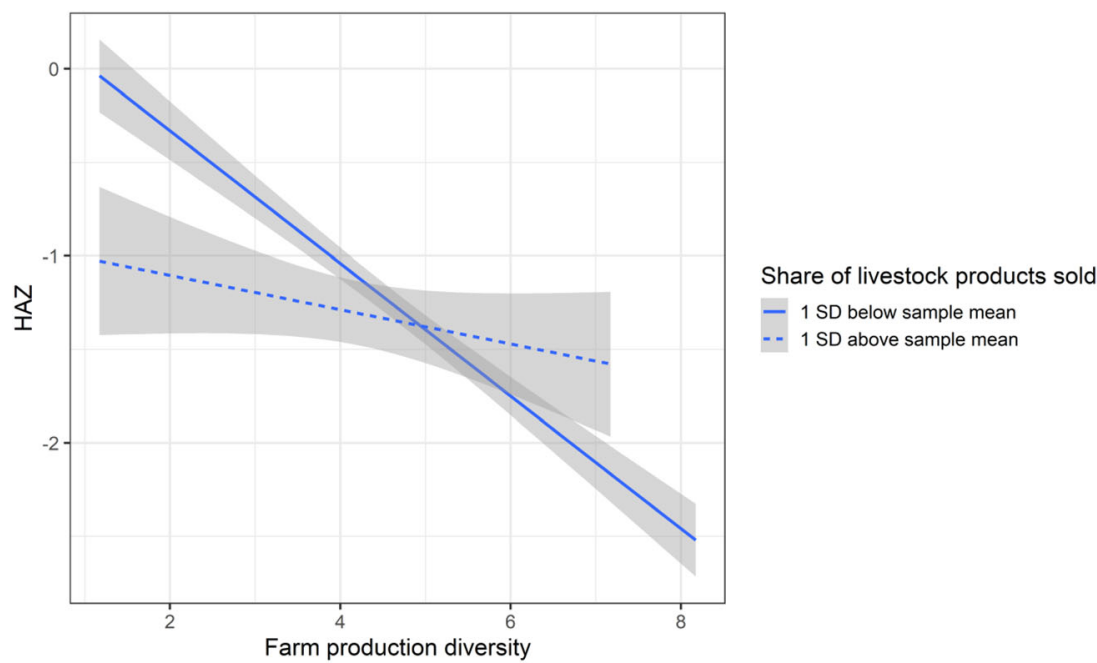


anthropometry because children age out of samples when a survey is repeated every 2 or 3 years. Fixed effects models also come at a cost of decreased signal in the data because the estimated variation in height-for-age and weight-for-height is diminished by the introduction of child- and time fixed effects. Given that our dataset includes at most three observation per child, the within-child variation in height-for-age and weightfor-height is not large to begin with. Still, fixed effects models better account for omitted variables and thus produce more reliable estimates compared to cross-sectional models. Another limitation is that we focus on food security as one out of many potential causes of child malnutrition, but it may or may not be the biggest contributor to child malnutrition. Finally, we were not able to report results separately for younger (6-23-month-old) and older ( $\geq 24$ month-old) children, and we acknowledge that the associations between farm production diversity and anthropometric indicators in these two groups may go in different directions as younger children might be partially protected from the detrimental effect of droughts by breastfeeding.

\section{Discussion}

In this study we investigated the relationship between farm production diversity and farm production composition on children's growth associated with food security - height-for-age and weight-for-age. The results demonstrate that in general, increases in farm production diversity are associated with increases in child height-for-age. Farm production composition matters too - growing more cereal crops relative to other crop varieties is associated with higher HAZ for children. In addition, children HAZ also benefits from household production of dairy and meat. Cereal crops are staples in the Ethiopian diets, and dairy is an important source of animal protein (especially for older children who no longer receive protein from mother's milk as opposed to younger breastfed children) (Neumann et al., 2002; Taffesse et al., 2012). These findings are in line with previous research and show, for example, that farm-level interventions associated with dairy could have positive impacts on child health.

We also find important caveats in these relationships, with implications for household and individual resilience in the face of adverse environmental conditions. While the relationship between farm production diversity and HAZ is positive overall, it is modified by exposure to suboptimal rainfall. Specifically, the interaction between suboptimal rainfall and farm production diversity has a negative slope, indicating that, at the average level of farm production diversity, children from areas that received less than normal rainfall have lower HAZ. This finding might be indicative of a certain level of diminishing returns to increasing farm production diversity wherein growing too many crops may decrease household income, undermine food security, and, consequently, child nutrition because of unrealized benefits from specializing in a few crops (Sibhatu et al., 2015).

We speculate that investing in a more diverse crop portfolio during suboptimal rainfall conditions may be detrimental to child nutrition because of diminished food security and changes in childcare practices. If suboptimal rainfall is detrimental to crop yields and livestock, then households with more diverse crops and animals on the farm might lose out on more food groups (including foods essential for child nutrition such as cereals, pulses, and animal protein) relative to households that produce only a few food groups. As a result, the diversity of available food would be impacted, with negative implications for food consumption and child nutrition. As for childcare practices, households that produce many crop and livestock species might experience increased demands for their time from tending to their crops/livestock more during bad rainfall, which could take time away from caring for young children (e.g., breastfeeding). However, empirical evidence indicates that positive rainfall shocks, not negative, are associated with decreases in the duration of breastfeeding through increased demand on mother's time (Randell et al., 2021; Thai \& Falaris, 2014). It appears that the need to balance childcare and food production might also exist during negative rainfall shocks, when crops and livestock require more care, but more research is needed to test this. Our results show that livestock sales may at least partially mitigate the negative association between farm production diversity and child HAZ during adverse rainfall conditions, possibly via livestock sales (Hoddinott \& Kinsey, 2001).

Another caveat is that there is evidence pointing to nonlinear relationships between farm-level agricultural production diversity and household-level food security (Bakhtsiyarava et al., 2021; Sibhatu et al., 2015). Future research should investigate these potential non-linearities and thresholds in the association between production diversity and child nutritional outcomes.

Interestingly, we did not observe a significant effect modification by distance to the market or presence of the market in the community, although livestock sales imply a certain level of household integration into markets. According to the data, households in villages with no large weekly market sell a higher share of their livestock products than those with a large market in the village $(22 \%$ vs. $18 \%, p<0.001)$, which indicates that households may sell their products elsewhere, including markets outside of their village and/or informal sales to fellow community residents. In that respect, our measure of livestock sales provides a better understanding of how household market participation is associated with better child linear growth compared to a binary measure of market in the village or distance to market.

The measure of village-level production diversity and composition exhibited the same relationships with the outcomes as 
household-level measures. Similar to the household measure, increases in village-level production diversity during a drought are negatively related to child height-for-age. The same direction of the relationship for both levels of measurement may suggest that droughts impact most village households in the same way and diminish within-community inequality (Thiede, 2014), with negative implications for food security and child nutrition. Given low rates of technology adoption throughout Ethiopia (Jayne et al., 2010; Morris et al., 2007), it is plausible that rainfall shocks will affect food security and child nutrition for most households negatively, which would also imply that the more affected households would not be able to maintain adequate diets by buying food from the less-affected farmers on the markets. These are speculations, and future research should analyze farm-level and village-level agricultural production diversity in parallel.

Overall, these results indicate that increasing farm production diversity is a viable strategy to improve child nutrition, but adverse climatic conditions may modify that relationship, in which case strategies such as livestock sales may mitigate the negative effect on child nutrition. It is important to note that HAZ as an indicator of chronic child malnutrition turned out to be more sensitive to the measures of farm production diversity and farm production composition than WHZ, a measure of acute malnutrition. While we analyzed child WHZ, we did not find many significant associations for that measure (results for WHZ can be found in the Supplementary Material). A possible explanation for this is that WHZ is more of an immediate measure of a child's weight relative to height and thus reflects short-term nutrition, whereas the measures of agricultural production diversity we used reflect a general, averaged household food security situation over a longer time scale. Being reflective of the general household food situation, our agricultural production diversity measures may therefore be poor predictors of child WHZ and be better positioned to explain within-child variation in child HAZ, as shown by our results.

Supplementary Information The online version contains supplementary material available at https://doi.org/10.1007/s12571-021-01173-9.

Code availability $\mathrm{R}$ code to perform the analysis is available upon request.

Authors' contributions $\mathrm{MB}$ and $\mathrm{KG}$ designed the study, MB processed data and performed statistical analyses, and $\mathrm{MB}$ and $\mathrm{KG}$ wrote the paper.

Funding The authors gratefully acknowledge support from a National Science Foundation INFEWS grant (Award \#1639214).

Data availability The LSMS data are publicly available at https:// microdata.worldbank.org/index.php/catalog/lsms\# $r=\&$ collection= $\&$ country $=66 \&$ dtype $=\&$ from $=1890 \&$ page $=1 \& \mathrm{ps}=\&$ sid $=\&$ sk $=\&$ sort by $=$ nation $\&$ sort_order $=\&$ to $=2017 \&$ topic $=\& v i e w=s \& v k=$

CHIRPS data are publicly available at https://www.chc.ucsb.edu/data

\section{Declarations}

Conflict of interest The authors declare no conflict of interest.

Open Access This article is licensed under a Creative Commons Attribution 4.0 International License, which permits use, sharing, adaptation, distribution and reproduction in any medium or format, as long as you give appropriate credit to the original author(s) and the source, provide a link to the Creative Commons licence, and indicate if changes were made. The images or other third party material in this article are included in the article's Creative Commons licence, unless indicated otherwise in a credit line to the material. If material is not included in the article's Creative Commons licence and your intended use is not permitted by statutory regulation or exceeds the permitted use, you will need to obtain permission directly from the copyright holder. To view a copy of this licence, visit http://creativecommons.org/licenses/by/4.0/.

\section{References}

Abafita, J., \& Kim, K.-R. (2014). Determinants of household food security in rural Ethiopia: An empirical analysis. Journal of Rural Development/Nongchon-Gyeongje, 37(1071-2016-86950), 129.

Ali, D. A., Dercon, S., \& Gautam, M. (2011). Property rights in a very poor country: tenure insecurity and investment in Ethiopia. Agricultural Economics, 42(1), 75-86.

Ayele, Z., \& Peacock, C. (2003). Improving access to and consumption of animal source foods in rural households: The experiences of a women-focused goat development program in the highlands of Ethiopia. The Journal of Nutrition, 133(11), 3981S-3986S.

Azzarri, C., Zezza, A., Haile, B., \& Cross, E. (2015). Does livestock ownership affect animal source foods consumption and child nutritional status? Evidence from rural Uganda. The Journal of Development Studies, 51(8), 1034-1059.

Bakhtsiyarava, M., Williams, T. G., Verdin, A., \& Guikema, S. D. (2021). A nonparametric analysis of household-level food insecurity and its determinant factors: exploratory study in Ethiopia and Nigeria. Food Security, 13(1), 55-70.

Belachew, T., Lindstrom, D., Gebremariam, A., Jira, C., Hattori, M. K., Lachat, C., Huybregts, L., \& Kolsteren, P. (2012). Predictors of chronic food insecurity among adolescents in Southwest Ethiopia: A longitudinal study. BMC Public Health, 12(1), 604.

Berti, P. R., Krasevec, J., \& FitzGerald, S. (2004). A review of the effectiveness of agriculture interventions in improving nutrition outcomes. Public Health Nutrition, 7(5), 599-609. https://doi.org/10. 1079/phn2003595.

Beyene, F., \& Muche, M. (2010). Determinants of food security among rural households of Central Ethiopia: An empirical analysis. Quarterly Journal of International Agriculture, 49(4), 299.

Beyero, M., Hodge, J., \& Lewis, A. (2015). Leveraging agriculture for nutrition in East Africa (LANEA) country report-Ethiopia.

Black, R. E., Allen, L. H., Bhutta, Z. A., Caulfield, L. E., De Onis, M., Ezzati, M., . . . Group, M. a. C. U. S. (2008). Maternal and child undernutrition: Global and regional exposures and health consequences. The Lancet, 371(9608), 243-260.

Bogale, A., \& Shimelis, A. (2009). Household level determinants of food insecurity in rural areas of Dire Dawa, eastern Ethiopia. African Journal of Food, Agriculture, Nutrition and Development, 9(9).

Bogale, A., Taeb, M., \& Endo, M. (2006). Land ownership and conflicts over the use of resources: Implication for household vulnerability in eastern Ethiopia. Ecological Economics, 58(1), 134-145. 
Brown, M. E., Antle, J. M., Backlund, P., Carr, E. R., Easterling, W. E., Walsh, M. K., ... Bellemare, M. F. (2015). Climate Change, Global Food Security, and the U.S. Food System (146 pages). Available online at http://www.usda.gov/oce/climate_change/ FoodSecurity2015Assessment/FullAssessment.pdf. https://doi.org/ 10.7930/J0862DC7.

Brown, M. E., Backer, D., Billing, T., White, P., Grace, K., Doocy, S., \& Huth, P. (2020). Empirical studies of factors associated with child malnutrition: Highlighting the evidence about climate and conflict shocks. Food Security, 1-12.

Carletto, C., \& Gourlay, S. (2019). A thing of the past? Household surveys in a rapidly evolving (agricultural) data landscape: Insights from the LSMS-ISA. Agricultural Economics, 50, 51-62.

Carletto, G., Ruel, M., Winters, P., \& Zezza, A. (2015). Farm-level pathways to improved nutritional status: Introduction to the special issue. The Journal of Development Studies, 51(8), 945-957. https://doi. org/10.1080/00220388.2015.1018908.

Carter, M. R., Little, P. D., Mogues, T., \& Negatu, W. (2007). Poverty traps and natural disasters in Ethiopia and Honduras. World Development, 35(5), 835-856.

Chegere, M. J., \& Stage, J. (2020). Agricultural production diversity, dietary diversity and nutritional status: Panel data evidence from Tanzania. World Development, 129, 104856.

Croissant, Y., \& Millo, G. (2008). Panel data econometrics in R: The plm package. Journal of Statistical Software, 27(2), 1-43.

CSA \& World Bank (2017). Living standards measurement studyintegrated surveys on agriculture (LSMS-ISA)/Ethiopia Socioeconomic Survey (ESS). Available at: https://microdata. worldbank.org/index.php/catalog/lsms\#_r=\&collection=\&country= $66 \&$ dtype $=\&$ from $=1890 \&$ page $=1 \& \mathrm{ps}=\&$ sid $=\&$ sk $=\&$ sort $\_b y=$ nation \&sort_order $=\&$ to $=2017 \&$ topic $=\& v i e w=s \& v k=:$ Central Statistical Agency of Ethiopia, World Bank.

CSA-ICF. (2017). Ethiopia Demographic and Health Survey 2016. Addis Ababa, Ethiopia, and Rockville, Maryland, USA.

Demeke, A. B., Keil, A., \& Zeller, M. (2011). Using panel data to estimate the effect of rainfall shocks on smallholders food security and vulnerability in rural Ethiopia. Climatic Change, 108(1-2), 185206

Demeke, M., Guta, F., Ferede, T., \& Addis Ababa University. (2004). Agricultural development in Ethiopia: Are there alternatives to food aid? Department of Economics, Addis Ababa University. www. sarpn.org.za/documents/d0001583/FAO2005_Casestudies Ethiopia.pdf.

Devendra, C. (2005). Small ruminants in Asia; Contribution to food security, poverty alleviation and opportunities for productivity enhancement. In Proceeding of international workshop on small ruminant production and development in South East Asia (pp. 19-32). MEKARN, Nong Lam, HCMC, Vietnam.

Devereux, S., \& Sussex, I. (2000). Food insecurity in Ethiopia: Institute for Development Studies.

Dewey, K. G., \& Begum, K. (2011). Long-term consequences of stunting in early life. Maternal \& Child Nutrition, 7, 5-18.

Dillon, A., McGee, K., \& Oseni, G. (2015). Agricultural production, dietary diversity and climate variability. The Journal of Development Studies, 51(8), 976-995.

Dorelien, A. M. (2015). Effects of birth month on child health and survival in sub-Saharan Africa. Biodemography and Social Biology, 61(2), 209-230. https://doi.org/10.1080/19485565.2015.1032399.

EPAR. (2019). AgDev priority indicators: Summary statistics round 2 (v7.2). University of Washington, Evans School of Policy Analysis and Research Group (EPAR).

FAO. (1996). Rome declaration on world food security and world food summit plan of action. Food and Agriculture Organization of the United Nations.
FAO. (2017). Ethiopia: Drought response plan and priorities in 2017 (pp. 1-7). Food and Agriculture Organization of the United Nations.

Feleke, S. T., Kilmer, R. L., \& Gladwin, C. H. (2005). Determinants of food security in southern Ethiopia at the household level. Agricultural Economics, 33(3), 351-363.

Frelat, R., Lopez-Ridaura, S., Giller, K. E., Herrero, M., Douxchamps, S., Djurfeldt, A. A., et al. (2016). Drivers of household food availability in sub-Saharan Africa based on big data from small farms. Proceedings of the National Academy of Sciences, 113(2), 458-463.

Funk, C., Peterson, P., Landsfeld, M., Pedreros, D., Verdin, J., Shukla, S., Husak, G., Rowland, J., Harrison, L., Hoell, A., \& Michaelsen, J. (2015). The climate hazards infrared precipitation with stations - A new environmental record for monitoring extremes. Scientific Data, 2(1), 150066. https://doi.org/10.1038/sdata.2015.66.

Funk, C., Rowland, J., Eilerts, G., Kebebe, E., Biru, N., White, L., \& Galu, G. (2012). A climate trend analysis of Ethiopia. US Geological Survey, Fact Sheet, 3053.

Gillespie, S., \& van den Bold, M. (2017). Agriculture, food systems, and nutrition: Meeting the challenge. Global Challenges, 1(3), 1600002.

Headey, D., \& Hirvonen, K. (2016). Is exposure to poultry harmful to child nutrition? An observational analysis for rural Ethiopia. PLoS One, 11(8), e0160590.

Headey, D., Nguyen, P., Kim, S., Rawat, R., Ruel, M., \& Menon, P. (2017). Is exposure to animal feces harmful to child nutrition and health outcomes? A multicountry observational analysis. The American Journal of Tropical Medicine and Hygiene, 96(4), 961969.

Hirvonen, K., \& Hoddinott, J. (2017). Agricultural production and children's diets: Evidence from rural Ethiopia. Agricultural Economics, 48(4), 469-480.

Hirvonen, K., Sohnesen, T. P., \& Bundervoet, T. (2020). Impact of Ethiopia's 2015 drought on child undernutrition. World Development, 131, 104964.

Hoddinott, J., Headey, D., \& Dereje, M. (2015). Cows, missing milk markets, and nutrition in rural Ethiopia. The Journal of Development Studies, 51(8), 958-975.

Hoddinott, J., \& Kinsey, B. (2001). Child growth in the time of drought. Oxford Bulletin of Economics and Statistics, 63(4), 409-436.

Holden, S. T., \& Ghebru, H. (2016). Land tenure reforms, tenure security and food security in poor agrarian economies: Causal linkages and research gaps. Global Food Security, 10, 21-28.

Hsiao, C. (2007). Panel data analysis-Advantages and challenges. Test, 16(1), 1-22.

IFPRI. (2016). Global nutrition report 2016: From promise to impact: Ending malnutrition by 2030. International Food Policy Research Institute.

Islam, A. H. M. S., von Braun, J., Thorne-Lyman, A. L., \& Ahmed, A. U. (2018). Farm diversification and food and nutrition security in Bangladesh: Empirical evidence from nationally representative household panel data. Food Security, 10(3), 701-720.

Jayne, T. S., Mather, D., \& Mghenyi, E. (2010). Principal challenges confronting smallholder agriculture in sub-Saharan Africa. World Development, 38(10), 1384-1398.

Jones, A. D. (2017a). Critical review of the emerging research evidence on agricultural biodiversity, diet diversity, and nutritional status in low-and middle-income countries. Nutrition Reviews, 75(10), 769 782.

Jones, A. D. (2017b). On-farm crop species richness is associated with household diet diversity and quality in subsistence-and market-oriented farming households in Malawi. The Journal of Nutrition, 147(1), 86-96.

Jones, A. D., Ngure, F. M., Pelto, G., \& Young, S. L. (2013). What are we assessing when we measure food security? A compendium and review of current metrics. Advances in Nutrition, 4(5), 481-505. 
Jones, A. D., Shrinivas, A., \& Bezner-Kerr, R. (2014). Farm production diversity is associated with greater household dietary diversity in Malawi: Findings from nationally representative data. Food Policy, 46, 1-12.

Josephson, A. L., Ricker-Gilbert, J., \& Florax, R. J. (2014). How does population density influence agricultural intensification and productivity? Evidence from Ethiopia. Food Policy, 48, 142-152.

Koppmair, S., Kassie, M., \& Qaim, M. (2017). Farm production, market access and dietary diversity in Malawi. Public Health Nutrition, 20(2), 325-335.

Kumar, N., Harris, J., \& Rawat, R. (2015). If they grow it, will they eat and grow? Evidence from Zambia on agricultural diversity and child undernutrition. The Journal of Development Studies, 51(8), 1060 1077.

Lobell, D. B., Azzari, G., Burke, M., Gourlay, S., Jin, Z., Kilic, T., \& Murray, S. (2019). Eyes in the sky, boots on the ground: Assessing satellite-and ground-based approaches to crop yield measurement and analysis. American Journal of Agricultural Economics.

Michler, J. D., \& Josephson, A. L. (2017). To specialize or diversify: Agricultural diversity and poverty dynamics in Ethiopia. World Development, 89, 214-226.

Mishra, A. K., \& Singh, V. P. (2010). A review of drought concepts. Journal of Hydrology, 391(1-2), 202-216.

Mohamed, A. A. (2017). Food security situation in Ethiopia: A review study. Int J Health Econ Policy, 2(3), 86-96.

Morris, M., Kelly, V. A., Kopicki, R. J., \& Byerlee, D. (2007). Fertilizer use in African agriculture: Lessons learned and good practice guidelines: The World Bank.

Muller, C. (2009). Do agricultural outputs of partly autarkic peasants affect their health and nutrition? Evidence from Rwanda. Food Policy, 34(2), 166-175.

Neumann, C., Harris, D. M., \& Rogers, L. M. (2002). Contribution of animal source foods in improving diet quality and function in children in the developing world. Nutrition Research, 22(1-2), 193220.

Okike, I., Jabbar, M. A., Abate, G., \& Ketema, L. (2005). Household and environmental factors influencing anthropometric outcomes in preschool children in a rural Ethiopian community. Ecology of Food and Nutrition, 44(3), 167-187.

Phalkey, R. K., Aranda-Jan, C., Marx, S., Höfle, B., \& Sauerborn, R. (2015). Systematic review of current efforts to quantify the impacts of climate change on undernutrition. Proceedings of the National Academy of Sciences, 112(33), E4522-E4529.

Philip, S., Kew, S. F., Jan van Oldenborgh, G., Otto, F., O'Keefe, S., Haustein, K., et al. (2018). Attribution analysis of the Ethiopian drought of 2015. Journal of Climate, 31(6), 2465-2486.

Pinstrup-Andersen, P. (2013). Nutrition-sensitive food systems: From rhetoric to action. The Lancet, 382(9890), 375-376.

$\mathrm{R}$ Core Team. (2019). $R$ : A language and environment for statistical computing. R Foundation for statistical computing. https://www.Rproject.org/.

Randell, H., Grace, K., \& Bakhtsiyarava, M. (2021). Climatic conditions and infant care: implications for child nutrition in rural Ethiopia. Population and Environment. https://doi.org/10.1007/ s11111-020-00373-3.

Remans, R., DeClerck, F. A., Kennedy, G., \& Fanzo, J. (2015). Expanding the view on the production and dietary diversity link: Scale, function, and change over time. Proceedings of the National Academy of Sciences, 112(45), E6082-E6082.

Remans, R., Flynn, D. F., DeClerck, F., Diru, W., Fanzo, J., Gaynor, K., et al. (2011). Assessing nutritional diversity of cropping systems in African villages. PLoS One, 6(6), e21235.

Ruel, M. T., Alderman, H., \& Maternal Child Nutr Study, G. (2013). Nutrition-sensitive interventions and programmes: How can they help to accelerate progress in improving maternal and child nutrition? Lancet, 382(9891), 536-551. https://doi.org/10.1016/ s0140-6736(13)60843-0.

Ruel, M. T., Quisumbing, A. R., \& Balagamwala, M. (2018). Nutritionsensitive agriculture: What have we learned so far? Global Food Security, 17, 128-153.

Sansoucy, R. (1995). Livestock-a driving force for food security and sustainable development. World, 3074(5389), 1035.

Schumacher, D. (2020). "anthro": Computation of the WHO child growth standards. R package version 0.9.4.

Shively, G., \& Sununtnasuk, C. (2015). Agricultural diversity and child stunting in Nepal. Journal of Development Studies, 51(8), 10781096. https://doi.org/10.1080/00220388.2015.1018900.

Shively, G. E. (2017). Infrastructure mitigates the sensitivity of child growth to local agriculture and rainfall in Nepal and Uganda. Proceedings of the National Academy of Sciences of the United States of America, 114(5), 903-908. https://doi.org/10.1073/pnas. 1524482114

Shrimpton, R., Victora, C. G., de Onis, M., Lima, R. C., Blössner, M., \& Clugston, G. (2001). Worldwide timing of growth faltering: Implications for nutritional interventions. Pediatrics, 107(5), e75e75.

Sibhatu, K. T., Krishna, V. V., \& Qaim, M. (2015). Production diversity and dietary diversity in smallholder farm households. Proceedings of the National Academy of Sciences, 112(34), 10657-10662.

Sibhatu, K. T., \& Qaim, M. (2018). Meta-analysis of the association between production diversity, diets, and nutrition in smallholder farm households. Food Policy, 77, 1-18.

Slavchevska, V. (2015). Agricultural production and the nutritional status of family members in Tanzania. The Journal of Development Studies, 51(8), 1016-1033.

Swindale, A., \& Bilinsky, P. (2006). Household dietary diversity score (HDDS) for measurement of household food access: Indicator guide. Food and Nutrition Technical Assistance Project, Academy for Educational Development.

Taffesse, A. S., Dorosh, P., \& Gemessa, S. A. (2012). Crop production in Ethiopia: Regional patterns and trends. Food and agriculture in Ethiopia: Progress and policy challenges, 53-83.

Thai, T. Q., \& Falaris, E. M. (2014). Child schooling, child health, and rainfall shocks: Evidence from rural Vietnam. Journal of Development Studies, 50(7), 1025-1037.

Thiede, B. C. (2014). Rainfall shocks and within-community wealth inequality: Evidence from rural Ethiopia. World Development, 64, 181-193.

Tobin, D., Jones, K., \& Thiede, B. C. (2019). Does crop diversity at the village level influence child nutrition security? Evidence from 11 sub-Saharan African countries. Population and Environment, 41(2), 74-97.

Torres-Reyna, O. (2007). Panel data analysis fixed and random effects using Stata (v. 4.2). Data \& Statistical Services, Priceton University.

Torres-Reyna, O. (2010). Getting started in fixed/random effects models using R. Data \& Statistical Services. Princeton University.

UNICEF. (1991). The UNICEF conceptual framework on malnutrition. United Nations Children's Fund.

Victora, C. G. (1992). The association between wasting and stunting: An international perspective. The Journal of Nutrition, 122(5), 11051110.

Victora, C. G., Adair, L., Fall, C., Hallal, P. C., Martorell, R., Richter, L., . . Group, M. a. C. U. S. (2008). Maternal and child undernutrition: Consequences for adult health and human capital. The Lancet, 371(9609), 340-357.

Victora, C. G., De Onis, M., Hallal, P. C., Blössner, M., \& Shrimpton, R. (2010). Worldwide timing of growth faltering: Revisiting implications for interventions. Pediatrics, 125(3), e473-e480.

WHO, \& de Onis, M. (2006). Assessment of differences in linear growth among populations in the WHO multicentre growth reference study. Acta Paediatrica, 95, 56-65.

Workneh, A., Getahun, E., Tibbo, M., Mamo, Y., \& Rege, J. (2003). Current state of knowledge on characterization of farm animal 
genetic resources in Ethiopia. Farm animal biodiversity in Ethiopia: Status and prospects. Paper presented at the Asfaw Yimegnuhal and Tamrat Degefa (eds), Proceedings of the 11th annual conference of the Ethiopian Society of Animal Production (ESAP) held in Addis Ababa, Ethiopia, 28-30 August 2003.

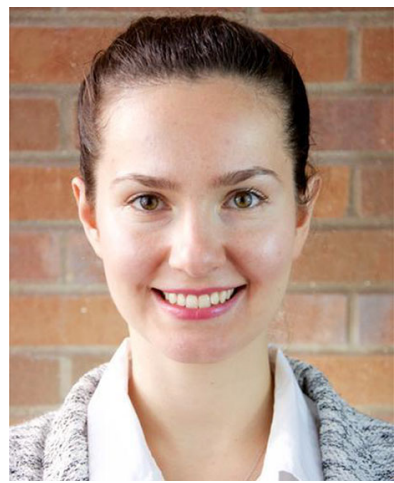

Maryia Bakhtsiyarava is a postdoctoral scholar at the Institute of $\mathrm{Urb}$ an and Regiona 1 Development at the University of California - Berkeley. She completed her PhD at the Department of Geography, Environment and Society at the University of Minnesota in Summer 2020. Maryia's doctoral work analyzed how householdlevel food (in)security interacts with children's nutrition outcomes and relates to households' livelihood strategies manifested through their agricultural activities in the context of climate variability.

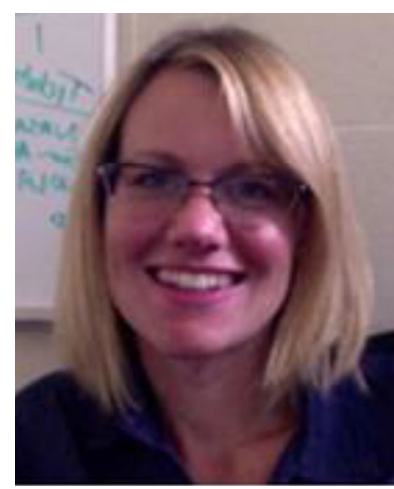

Kathryn Grace is an Associate Professor at the Department of Geography, Environment and Society at the University of Minnesota. Her research focuses on food insecurity, children's health and women's health under climate change. She also studies how women manage their nutritional needs while pregnant and breastfeeding. As part of this research, she investigates the decisions that women and men make regarding childbearing and contraceptive use while coping with food insecurity. Her research is primarily focused in some of the poorest countries in the world in West Africa, East Africa and Central America. 